\title{
Triceps motor branch transfer for isolated traumatic pediatric axillary nerve injuries
}

\author{
Harvey Chim, MBBS, ${ }^{1}$ Michelle F. Kircher, BS, ${ }^{1}$ Robert J. Spinner, MD, ${ }^{2}$ Allen T. Bishop, MD, ${ }^{1}$ \\ and Alexander Y. Shin, MD' \\ 1Division of Hand Surgery, Department of Orthopedic Surgery, and 'Department of Neurosurgery, Mayo Clinic, Rochester, \\ Minnesota
}

\begin{abstract}
OBJECT Transfer of the triceps motor branch has been used for treatment of isolated axillary nerve palsy in the adult population. However, there are no published data on the effectiveness of this procedure in the pediatric population with traumatic injuries. The authors reviewed demographics and outcomes in their series of pediatric patients who underwent this procedure.
\end{abstract}

METHODS Six patients ranging in age from 10 to 17 years underwent triceps motor branch transfer for the treatment of isolated axillary nerve injuries between 4 and 8 months after the inciting injury. Deltoid muscle strength was evaluated using the modified British Medical Research Council (MRC) grading system. Shoulder abduction at last follow-up was measured.

RESULTS The mean duration of follow-up was 38 months. The average postoperative MRC grading of deltoid muscle strength was $3.6 \pm 1.3$. The median MRC grade was 4 . One patient who did not achieve an MRC grade of 3 suffered multiple injuries from high-velocity trauma. Unlike in the adult population, age, body mass index of the patient, and delay from injury to surgery were not significant factors affecting the outcome of the procedure.

CONCLUSIONS In the pediatric population with traumatic injuries, isolated axillary nerve injury treated with triceps motor branch transfer can result in good outcomes.

http://thejns.org/doi/abs/10.3171/2014.9.PEDS14245

KEY WORDS nerve transfer; triceps motor branch; axillary nerve injury; peripheral nerve

$\mathrm{P}$ EDIATRIC patients with traumatic brachial plexus injuries constitute only a small percentage of all brachial plexus lesions, and consisted of $1.1 \%$ of all injuries in a previous patient series. ${ }^{5}$ Rarer still are pediatric patients with isolated axillary nerve injuries. These injuries often occur after trauma to the shoulder or less frequently as a complication of shoulder surgery. ${ }^{15,17}$ They may initially also present with a more extensive pattern of brachial plexus injury, with spontaneous recovery of other components resulting in residual deltoid muscle weakness that necessitates surgical intervention.

While nerve grafting has been recommended for repair of axillary nerve lesions, ${ }^{10,18}$ the triceps motor branch transfer to the axillary nerve for reinnervation of the deltoid muscle, as initially described by Leechavengvongs et al. ${ }^{13,22}$ for treatment of lesions of the upper trunk, has been increasingly used in lieu of nerve grafting by our group and others ${ }^{3,7,12,19}$ for treatment of isolated axillary nerve lesions. The triceps motor branch transfer has the advantage of having the donor nerve much closer to the deltoid, resulting in a shorter distance required for nerve growth to the motor end plate. In theory, this results in faster and better nerve recovery. ${ }^{8}$ In addition, as many axillary nerve injuries occur in the quadrilateral space, nerve grafts of at least $8 \mathrm{~cm}$ in length are often required to bridge the gap..$^{1}$ It has been reported that patients with axillary nerve grafts longer than $7 \mathrm{~cm}$ had poorer recovery of shoulder abduction. ${ }^{11,20}$ Hence, nerve grafts may not be the best treatment option in long segment defects. As the triceps motor branch is synergistic to shoulder abduction and external rotation, the triceps motor branch transfer facilitates postoperative rehabilitation and reeducation of the deltoid muscle. ${ }^{2}$

ABBREVIATIONS BMI = body mass index; MRC = Medical Research Council; MVA = motor vehicle accident. SUBMITTED May 15, 2014. ACCEPTED September 29, 2014.

INCLUDE WHEN CITING Published online November 14, 2014; DOI: 10.3171/2014.9.PEDS14245.

DISCLOSURE The authors report no conflict of interest concerning the materials or methods used in this study or the findings specified in this paper. 
In the adult population treated with triceps motor branch transfer for isolated axillary nerve injuries, we found that a treatment delay of more than 9 months, increased age, and increased body mass index (BMI) adversely affected outcome of the procedure. ${ }^{12}$ In the pediatric population, however, there is little to no published data on outcomes of this procedure. Thus, the aim of this study was to present the outcomes of triceps motor branch transfer for isolated axillary nerve injury in a pediatric population with traumatic injuries.

\section{Methods}

\section{Study Population}

Following approval by the Mayo Clinic institutional review board, we performed a retrospective chart review of all patients treated with triceps motor branch transfer for isolated axillary nerve injuries between 2002 and 2012 in our institution. Inclusion criteria included all pediatric patients 17 years of age or younger at the time of surgery who had isolated axillary nerve injuries treated by transfer of the triceps motor branch of the radial nerve to the anterior division of the axillary nerve. All patients had at least 12 months of postoperative follow-up. Axillary nerve palsy was differentiated from suprascapular nerve palsy by using the active shoulder extension test and the abduction in internal rotation test. ${ }^{2}$ Electromyography was used to confirm the clinical diagnosis of axillary nerve injury. Findings included an absent axillary nerve motor response, as well as fibrillation potentials and absence of motor unit potentials in the deltoid muscle. Patients were considered for surgery at least 3 months after the initial injury, when there was no evidence of deltoid muscle function on physical examination or electromyographic evaluation. Exclusion criteria for this review included the presence of other nerve injuries requiring reconstruction. There was a total of 8 patients with isolated axillary nerve injuries in this time period, 6 of which were reconstructed with triceps motor branch transfer, which made up the cohort for this study.

\section{Surgical Technique}

The technique used has been previously described and was adapted from the technique described by Leechavengvongs et al. ${ }^{13}$ (Fig. 1). While a transaxillary approach can be used, we prefer a posterior approach because we believe that this provides a more direct access to the axillary and radial nerves. Briefly, a longitudinal incision was made on the posterior arm from the acromion to the middle of the arm. The deltoid was retracted anteriorly and the axillary nerve identified in the quadrilateral space. The axillary nerve was then mobilized proximally to identify anterior and posterior divisions. The anterior division was dissected free and divided as proximally as possible. The posterior division of the axillary nerve, which innervates the teres minor (a shoulder adductor), was left intact. The interval between the long and lateral heads of the triceps muscle was then opened to identify the radial nerve and its branches to the triceps. The motor branch to the long head of the triceps was then identified and confirmed with electrical stimulation. The triceps motor branch was then divided distally and sutured to the anterior division of the axillary nerve with 9-0 nylon sutures with the aid of an operating microscope, to ensure a tension-free coaptation. The nerve transfer was reinforced with a split collagen nerve tube (Neurotube, Integra Life Sciences) and fibrin glue (Tisseal, Baxter Inc.). Patients were immobilized for 3 weeks postoperatively to allow maturation of the nerve coaptation, after which passive range of motion and active range of motion were encouraged.

\section{Results}

Demographics of the 6 patients are presented in Table 1 . The average age was 14.2 years (range $10-17$ years). All patients were male. Mechanisms of injury included motor vehicle accidents (MVAs, $\mathrm{n}=2$ ) and motorcycle accidents $(n=2)$, with 1 patient each sustaining injury after snowboarding and after shoulder surgery. All patients underwent nerve reconstruction within 8 months after the inciting injury. Body mass index was relatively homogenous in our population, with all patients having a normal BMI (mean 21.7, range 18.4-24.5). Three patients (Cases 1,2 , and 4) had a number of concomitant injuries due to polytrauma caused by a high-velocity mechanism of injury. The mean length of follow-up was 38 months (range 12-74 months).

Outcome data are shown in Table 2. The modified British Medical Research Council (MRC) Grades 3+ and 4+ were indicated as 3.5 and 4.5 , respectively. Preoperative MRC grading of deltoid muscle strength was 0 in all patients. The average postoperative MRC grading of deltoid muscle strength was $3.6 \pm 1.3$. The median postoperative MRC grade was 4 . Five of the 6 patients regained MRC Grade 3 or greater deltoid muscle strength. One patient (Case 2) only regained MRC Grade 1 strength and eventually underwent shoulder tendon transfers to improve function. Figure 2 shows outcomes in 2 patients (Cases 3 and $5)$.

\section{Discussion}

Nerve transfers have been shown to be superior to traditional nerve grafting for restoration of shoulder and elbow function in adults with traumatic upper plexus palsy. ${ }^{8}$ In adults with axillary nerve palsy, a single-surgeon series reported similar outcomes with nerve grafts and triceps to axillary nerve transfer. ${ }^{23}$ Good outcomes following nerve grafting for treatment of isolated axillary nerve injury in adults have been reported. ${ }^{4,16}$ At this point, the literature on adult axillary nerve injuries does not appear to favor either nerve grafts or nerve transfers.

In the pediatric population with traumatic brachial plexus injury, little has been published about outcomes of nerve transfers or nerve grafts for axillary nerve injury. Isolated case series and case reports describe the efficacy of different nerve transfers in children following traumatic brachial plexus injuries. ${ }^{6,9,14,21}$ A small series of 4 pediatric patients with isolated axillary nerve injuries treated with nerve grafts or neurolysis recovered MRC Grade 4-5 function. ${ }^{6}$ While there are published data showing the efficacy of triceps motor branch transfer for treatment of isolated axillary nerve palsy in adults, ${ }^{3,7,12,13}$ there are few 


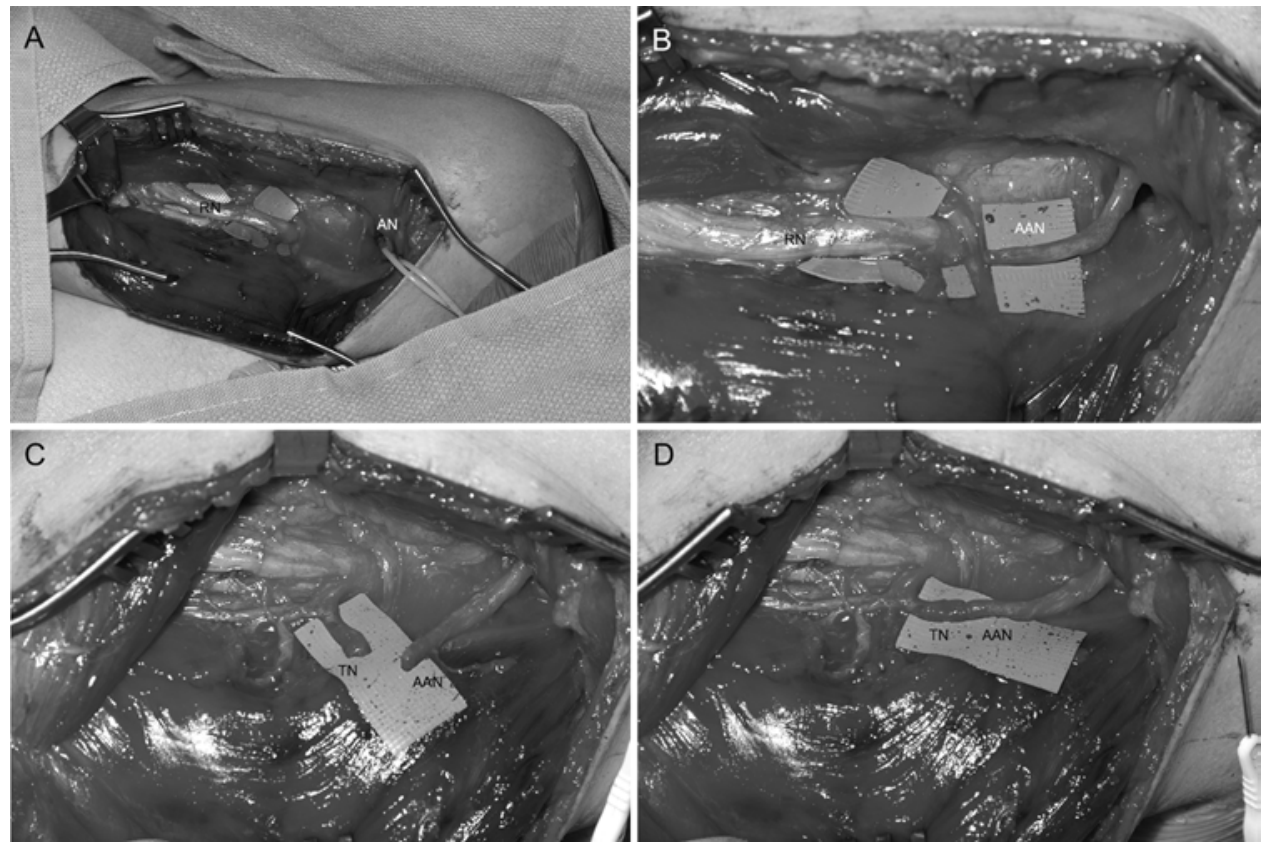

FIG. 1. Photographs of the surgical technique used. A: Incision over the posterior arm allows exposure of the radial nerve (RN) between the long and lateral heads of the triceps muscle. The axillary nerve (AN) is identified in the quadrangular space. B: The anterior division of the axillary nerve (AAN) is divided and rotated distally toward the triceps branch. C: The nerve to the long head of the triceps muscle (TN) is identified, separated from the radial nerve, and swung proximally. D: This nerve positioning allows a tension-free coaptation with the anterior division of the axillary nerve.

data demonstrating its efficacy in a pediatric population with traumatic injuries.

While many of these injuries may recover without surgical intervention after 3-4 months, a number of patients with persistent paralysis of the deltoid require surgical intervention. Due to the necessity of waiting for spontaneous recovery of isolated axillary nerve injuries, we encountered a delay of 4-8 months between the time of injury and surgery. When nerve grafts were used for treatment of axillary nerve lesions, a delay of 6 months resulted in poorer outcomes, ${ }^{4}$ while Terzis and Barmpitsioti ${ }^{20}$ reported that a denervation time of less than 4 months resulted in improved shoulder function following axillary nerve reconstruction. Hence, our preference is to perform nerve transfers for treatment of isolated axillary nerve injuries. Unlike nerve grafts, nerve transfers bypass the area of injury and decrease the time to regeneration, as the area of nerve coaptation is closer to the motor end plate. Transfer of the triceps motor branch to the anterior division of the axillary nerve prevents unnecessary regeneration of axons to the teres minor muscle and the superior lateral cutaneous nerve. ${ }^{13}$

In the adult population, advanced age, BMI of the patient, and delay from injury to surgery were found to correlate adversely with outcomes. However, we did not find this association in our series. This lack of an association is

TABLE 1. Demographic data of patients*

\begin{tabular}{|c|c|c|c|c|c|c|}
\hline $\begin{array}{l}\text { Case } \\
\text { No. }\end{array}$ & $\begin{array}{l}\text { Age } \\
\text { (yrs) }\end{array}$ & Injury & Associated Lesions & $\begin{array}{l}\text { Delay from } \\
\text { Injury to } \\
\text { Surgery (mos) }\end{array}$ & $\begin{array}{l}\text { Last } \\
\text { Follow-Up } \\
\text { (mos) }\end{array}$ & BMI \\
\hline 1 & 14 & MVA & Distal radius fracture, splenic laceration, lung contusion & 6 & 12 & 21.1 \\
\hline 2 & 17 & Snowboarding & Multiple cervical fractures, C5-6 ligamentous disruption & 4 & 22 & 18.4 \\
\hline 3 & 10 & Motorcycle & Glenohumeral fracture-dislocation & 7 & 74 & 24.5 \\
\hline 4 & 16 & MVA & $\begin{array}{l}\text { Splenic laceration, pulmonary embolism, pneumothorax, con- } \\
\text { tralateral suprascapular nerve neuropathy, contralateral } \\
\text { acromioclavicular joint separation, thoracic spine fractures }\end{array}$ & 7 & 65 & 22.4 \\
\hline 5 & 11 & Motorcycle & None & 6 & 34 & 21.7 \\
\hline 6 & 17 & $\begin{array}{l}\text { Shoulder surgery } \\
\text { (iatrogenic) }\end{array}$ & None & 8 & 21 & 22.2 \\
\hline
\end{tabular}

\footnotetext{
* All patients were male.
} 
TABLE 2. Patient outcome data

\begin{tabular}{|c|c|c|c|c|}
\hline \multirow{2}{*}{$\begin{array}{c}\text { Case } \\
\text { No. }\end{array}$} & \multicolumn{2}{|c|}{ MRC Grade } & \multirow{2}{*}{$\begin{array}{c}\text { Active Shoulder } \\
\text { Abduction }\left({ }^{\circ}\right)\end{array}$} & \multirow[b]{2}{*}{ Secondary Procedures } \\
\hline & Preop & Postop & & \\
\hline 1 & 0 & 4 & 150 & None \\
\hline 2 & 0 & 1 & 25 & Shoulder tendon transfers \\
\hline 3 & 0 & 4.5 & 180 & None \\
\hline 4 & 0 & 4.5 & 180 & None \\
\hline 5 & 0 & 4 & 180 & None \\
\hline 6 & 0 & 3.5 & 180 & None \\
\hline
\end{tabular}

likely a result of the homogenous patient cohort, in which all patients were male and had a normal BMI. The patient (Case 2) who underwent an operation the earliest, 4 months following the inciting injury, had the worst outcome. Insufficient data are available based on this small series to conclude if a longer delay from injury to surgery will result in similarly good outcomes.

This study has a number of limitations, chief of which is its retrospective nature and small sample size. The number of pediatric patients with isolated axillary nerve injury requiring reconstruction is extremely small, and this injury is rare in clinical practice, preventing the accrual of a large case series. In addition, with a longer followup duration, some of our patients might have experienced improved outcomes. However, many of our patients come from some distance away, and logistic and financial issues often prevent return for long-term follow-up.

\section{Conclusions}

Pediatric patients with traumatic isolated axillary nerve
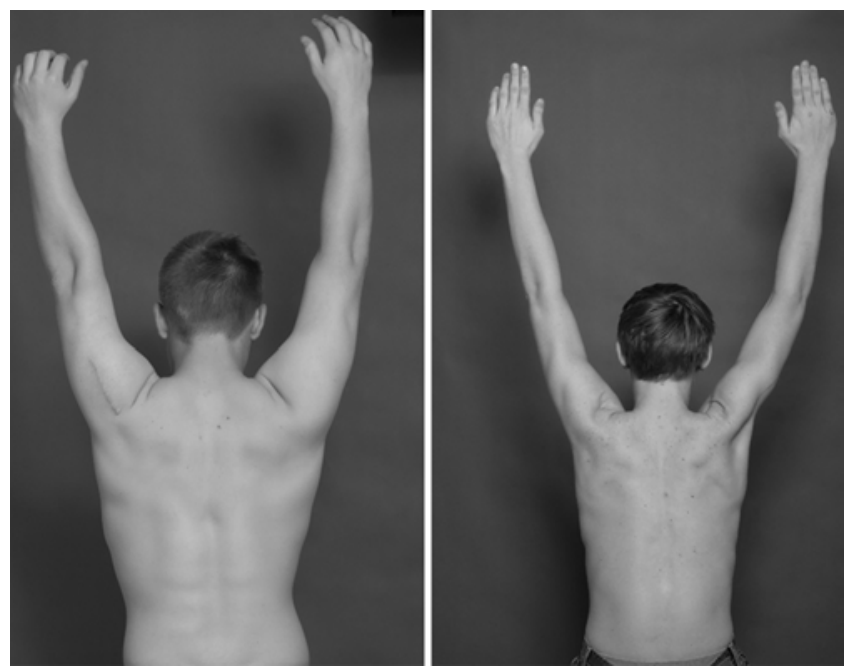

FIG. 2. Photographs showing full abduction of the left shoulder 74 months postoperatively in Case 3 (left), and full abduction of the right shoulder 34 months postoperatively in Case 5 (right). injury treated with triceps motor branch transfer can have good outcomes, but are not without failures.

\section{References}

1. Apaydin N, Tubbs RS, Loukas M, Duparc F: Review of the surgical anatomy of the axillary nerve and the anatomic basis of its iatrogenic and traumatic injury. Surg Radiol Anat 32:193-201, 2010

2. Bertelli JA, Ghizoni MF: Abduction in internal rotation: a test for the diagnosis of axillary nerve palsy. J Hand Surg Am 36:2017-2023, 2011

3. Bertelli JA, Kechele PR, Santos MA, Duarte H, Ghizoni MF: Axillary nerve repair by triceps motor branch transfer through an axillary access: anatomical basis and clinical results. J Neurosurg 107:370-377, 2007

4. Bonnard C, Anastakis DJ, van Melle G, Narakas AO: Isolated and combined lesions of the axillary nerve. A review of 146 cases. J Bone Joint Surg Br 81:212-217, 1999

5. Boome R: Traumatic brachial plexus surgery in children, in Gupta A, Kay SPJ, Scheker LR (eds): The Growing Hand: Diagnosis Management of the Upper Extremity in Children. London: Mosby, 2000, pp 653-657

6. Chen L, Gu YD, Hu SN, Xu JG, Xu L, Fu Y: Contralateral C7 transfer for the treatment of brachial plexus root avulsions in children-a report of 12 cases. J Hand Surg Am 32:96-103, 2007

7. Domínguez-Páez M, Socolovsky M, Di Masi G, Arráez-Sánchez MA: [Isolated traumatic injuries of the axillary nerve. Radial nerve transfer in four cases and literatura review.] Neurocirugia (Astur) 23:226-233, 2012 (Span)

8. Garg R, Merrell GA, Hillstrom HJ, Wolfe SW: Comparison of nerve transfers and nerve grafting for traumatic upper plexus palsy: a systematic review and analysis. J Bone Joint Surg Am 93:819-829, 2011

9. Gilbert A, Pivato G, Kheiralla T: Long-term results of primary repair of brachial plexus lesions in children. Microsurgery 26:334-342, 2006

10. Kline DG, Kim DH: Axillary nerve repair in 99 patients with 101 stretch injuries. J Neurosurg 99:630-636, 2003

11. Koller R, Rab M, Todoroff BP, Neumayer C, Haslik W, Stöhr $\mathrm{HG}$, et al: The influence of the graft length on the functional and morphological result after nerve grafting: an experimental study in rabbits. Br J Plast Surg 50:609-614, 1997

12. Lee JY, Kircher MF, Spinner RJ, Bishop AT, Shin AY: Factors affecting outcome of triceps motor branch transfer for isolated axillary nerve injury. J Hand Surg Am 37:23502356,2012

13. Leechavengvongs $\mathrm{S}$, Witoonchart $\mathrm{K}$, Uerpairojkit $\mathrm{C}$, Thuvasethakul P: Nerve transfer to deltoid muscle using the nerve to the long head of the triceps, part II: a report of 7 cases. $\mathbf{J}$ Hand Surg Am 28:633-638, 2003

14. Miller JH, Garber ST, McCormick DE, Eskandari R, Walker ML, Rizk E, et al: Oberlin transfer and partial radial to axillary nerve neurotization to repair an explosive traumatic injury to the brachial plexus in a child: case report. Childs Nerv Syst 29:2105-2109, 2013

15. Narakas AO: Paralytic disorders of the shoulder girdle. Hand Clin 4:619-632, 1988

16. Okazaki M, Al-Shawi A, Gschwind CR, Warwick DJ, Tonkin MA: Outcome of axillary nerve injuries treated with nerve grafts. J Hand Surg Eur Vol 36:535-540, 2011

17. Perlmutter GS: Axillary nerve injury. Clin Orthop Relat Res (368):28-36, 1999

18. Petrucci FS, Morelli A, Raimondi PL: Axillary nerve injuries -21 cases treated by nerve graft and neurolysis. J Hand Surg Am 7:271-278, 1982 
19. Teissier P, Lazerges C, Marès O, Bosch C, Chammas M: [Nerve transfer in isolated deltoid palsy: branch of the long head of the triceps to the axillary nerve.] Chir Main 31:239243, 2012 (Fr)

20. Terzis JK, Barmpitsioti A: Axillary nerve reconstruction in 176 posttraumatic plexopathy patients. Plast Reconstr Surg 125:233-247, 2010

21. Tyagi A, Drake J, Midha R, Kestle J: Axillary nerve injuries in children. Pediatr Neurosurg 32:226-229, 2000

22. Witoonchart K, Leechavengvongs S, Uerpairojkit C, Thuvasethakul P, Wongnopsuwan V: Nerve transfer to deltoid muscle using the nerve to the long head of the triceps, part I: an anatomic feasibility study. J Hand Surg Am 28:628-632, 2003

23. Wolf SW, Johnsen PH, Lee SK, Feinberg JH: Long-nerve grafts and nerve transfers demonstrate comparable outcomes for axillary nerve injuries. J Hand Surg Am 39:1351-1357, 2014

\section{Author Contributions}

Conception and design: Shin, Chim, Kircher. Acquisition of data: Chim, Kircher. Analysis and interpretation of data: Shin, Chim, Spinner, Bishop. Drafting the article: Chim. Critically revising the article: Shin, Chim, Spinner, Bishop. Reviewed submitted version of manuscript: Shin, Spinner, Bishop. Approved the final version of the manuscript on behalf of all authors: Shin. Statistical analysis: Chim. Administrative/technical/material support: Kircher. Study supervision: Shin, Spinner, Bishop.

\section{Correspondence}

Alexander Y. Shin, Department of Orthopedic Surgery, Division of Hand Surgery, Mayo Clinic, 200 1st St. SW, Rochester, MN 55905. email: shin.alexander@mayo.edu. 